\title{
Factors influencing awareness and attendance of traditional oral health care practices by residents of a peri-urban community in Ibadan, Nigeria
}

\author{
Folake Barakat Lawal, Juliana Obontu Taiwo, Gbemi Aderemi Oke
}

University of Ibadan, Department of Periodontology and Community Dentistry; University College Hospital, Department of Periodontology and Community Dentistry

\begin{abstract}
Background: In order to institute preventive programmes against harmful traditional oral health practices there is a need to identify targets.

Objectives: To investigate factors influencing awareness and attendance of traditional oral health practices by residents of a peri-urban community in Ibadan, Nigeria.

Methods: A cross-sectional study of adult residents selected by simple random sampling in a peri-urban community in Ibadan, Nigeria, was conducted over a period of six months. Information was obtained with interviewer administered questionnaires. Data were recorded using SPSS version 16 software.

Results: A total of $172(44.1 \%)$ respondents were aware of the existence of traditional healers for dental problems. Only $34(8.7 \%)$ participants had been to traditional healers on account of toothache. About $76.5 \%$ reported having relief after treatment with relapse occurring in 12 cases $(46.2 \%)$. Twenty (58.8\%) of these (34) participants said they would not choose this option of treating dental problems in future. Significant associations existed between knowing that traditional healers provided dental treatment and gender $(p=0.001)$ or history of dental problems $(p=0.008)$.

Conclusion: The study showed moderate awareness of traditional oral care practices in Ibadan, Nigeria as influenced by gender and previous dental problems.
\end{abstract}

Key words: Traditional, oral health care, practices, awareness, attendance, factors.

DOI: http://dx.doi.org/10.4314/ahs.v15i1.30

\section{Introduction}

In many African countries, access to oral health services is limited and teeth are often left untreated or are extracted to relieve pain or discomfort while in industrialised countries there has been a positive trend of reduction in tooth loss among adults in recent years ${ }^{1}$. The gap created by this inadequate coverage in dental services is more often than not filled by alternative oral health care services $^{2,3}$. Traditional practitioners are often the first point of contact in many sub-saharan communities, especially where some form of integration into modern

\section{Corresponding author:}

Folake Barakat Lawal

University of Ibadan, Department of

Periodontology and Community Dentistry

PMB 5017, Ibadan 200212, Nigeria.

Phone number - +234-8023658988,

Email address: folakemilawal@yahoo.com dental practice has occurred, and tooth extractions are often performed by them for painful tooth conditions ${ }^{4}$. Some researchers have reported positive outcome from the use of traditional alternative to oral care. One of such is the report on the medicinal value of Nigerian chewing sticks, Massularia acuminata and Distemonathus benthamianus ${ }^{5}$.

On the other hand complications may arise from some traditional health care practices leading to worsened dental appearance. One such example is qat, a leafy substance that is popular in several East African countries as well as in the Arabian Peninsula. It is commonly consumed, for its stimulant effect, in the form of tea, smoking, or chewing of the leaves. In addition to causing severe greenish discoloration of teeth, qat consumption can cause adverse effects such as oral mucosal lesions, dryness of the mouth, formation of cavities and development of periodontal disease ${ }^{1}$. Furthermore, certain cultural practices of cosmetic nature taking place in some African communities include; pinching of gums to make them darker in colour, brushing of children's gingiva with fresh herbs and drilling holes in the upper lips of girls ${ }^{6-8}$. These and other practices are associated with morbidities ${ }^{8,9}$. 
Despite this, individuals in the African community still the community and houses were selected using a table of random numbers. The occupants of the seler ment from traditional healers. Although it has been houses were then approached and if they consented, shown that $90 \%$ of those resident in the south-western they were recruited up to a maximum number of four parts of Nigeria are aware of traditional medical heal- adults in each house. The next house selected through ers ${ }^{10}$, very little information is available on dental care the sampling was then approached until the sample provided by traditional practitioners in the region. Sari- size was attained. Information was obtained with the ta and Tuominen ${ }^{11}$ in a study from Tanzania have doc- use of interviewer administered questionnaires, which umented a poor patronage of traditional dental practi- contained items on sociodemographic characteristics tioners by rural dwellers. It is, however, not known if of age, gender, marital status, educational status and the situation in a peri-urban community that has ready occupation. The questionnaire also sought information access to a primary oral health care centre will be similar. on the respondent's dental history.

Furthermore, the need arises to investigate the factors

that influence the awareness of adults about traditional The participants were asked if they were aware of or oral health care practices and reasons why they would had consulted traditional healers for dental problems seek traditional methods of treatment for dental prob- in the past, with responses recorded as "Yes" or "No" lems. Socio-cultural influences have been implicated as If they were aware, they were asked about the sources supporting the propagation of harmful practices when of information. They were also asked to shed light on traditional practitioners are visited.

This is exemplified by the practice of dental mutilation by the deliberate removal of incisor teeth of adolescents "seeking rite of passage into adulthood" in Western Cape, South Africa ${ }^{12}$. Elucidating the predictors of treatment seeking behaviour for these alternative forms of treatment will be a starting point towards primary oral health preventive programmes targeted at eliminating harmful traditional oral health care practices, while encouraging beneficial ones. The objectives of the study included describing the socio-demographic characteristics of residents of a peri-urban community in Ibadan, south-western Nigeria with knowledge of traditional oral health care practices and determining factors that influence awareness and service utilization.

\section{Methods}

A descriptive cross-sectional study of adult residents of a peri-urban community in Ibadan, Nigeria, was conducted over a period of six months. A total of 390 residents aged 18 years and above were selected through a simple random sampling technique. The sampling frame was obtained from a list of numbered houses in

A total of 390 participants were recruited for the study with a mean age of $38.6(\mathrm{SD}=15.6)$ years. The socio-demographic characteristics are as displayed in Table 1. Of the surveyed participants, 155 had experienced problems with their teeth in the past.

Table 1: Socio-demographic characteristics of the participants

\begin{tabular}{lll}
\hline Characteristic & Categories & No (\%) \\
\hline Age & $\leq 39$ years & $239(61.3)$ \\
& $>39$ years & $151(38.7)$ \\
\hline Gender & Male & $219(56.2)$ \\
& Female & $171(43.8)$ \\
\hline Marital status & Single & $21(51.4)$ \\
& Married & $280(71.8)$ \\
& Widowed & $21(5.4)$ \\
& Divorced & $1(0.3)$ \\
\hline Educational status & None & $59(15.1)$ \\
& Primary school (6th grade) & $125(32.1)$ \\
& Secondary school (12th grade) & $173(44.4)$ \\
& Tertiary education & $33(8.5)$ \\
\hline Occupation & Skilled workers & $48(12.3)$ \\
& Unskilled workers & $286(73.3)$ \\
& Dependants & $56(14.4)$ \\
\hline
\end{tabular}

Awareness of traditional healers for dental problems

A total of 172 respondents were aware of the existence of traditional healers for dental problems. The majority (93) knew about them through friends, 46 through mass or electronic media, 20 heard about them throug family members and 13 through sign posts meant for advertisement or when 'medicines' were being hawked. The reasons given for consulting the healers included: cheaper than conventional dental care $(34.9 \%)$, cultural and family practices $(20.3 \%)$, medicines are more potent $(7.6 \%)$ and proximity compared to orthodox dental clinics $(5.8 \%)$. Some of the participants $(17.4 \%)$ gave lack of awareness on alternatives to the traditional healers as the main reason.

\section{Use of traditional healers for dental care}

Of the participants, 34 had been to traditional healers on account of dental problems in the past. All visits were made for toothache. Most $(76.5 \%)$ of the healers were located within easy reach of the clients. The medicines administered ranged from solids through semi-solid to liquids. It was common practice to extract "worms" from the painful sites and 13 of the 34 participants who had received traditional dental treatment claimed such. A large proportion of the respondents $(76.5 \%)$ report ed having relief after treatment even though there was a relapse following treatment in $46.2 \%$. The remaining $23.5 \%$ did not experience relief from pain even after the use of concoctions. A total of 14 participant said they would choose this option of treating dental problems in future while 20 responded otherwise.

Socio-demographic characteristics and awarenes of traditional healers for dental treatment

The proportion of males $(29.0 \%)$ who knew that some traditional healers gave dental treatment was higher than that of females $(15.1 \%) p=0.001$. There was no relationship between status of awareness and participants age, marital status, educational status and occupational class as shown in Table 2. 


\begin{tabular}{|c|c|c|c|c|c|}
\hline \multirow[b]{2}{*}{ Variable } & \multicolumn{3}{|c|}{ Awareness of traditional dental healers } & \multirow[b]{2}{*}{$x^{2}$} & \multirow[b]{2}{*}{ p value } \\
\hline & $\begin{array}{l}\text { Aware } \\
\text { No (\%) }\end{array}$ & $\begin{array}{l}\text { Not aware } \\
\text { No }(\%)\end{array}$ & $\begin{array}{l}\text { Total } \\
\text { No }(\%)\end{array}$ & & \\
\hline $\begin{array}{l}\text { Age group (years) } \\
<39\end{array}$ & & & & 2.404 & \\
\hline $\begin{array}{l}\leq 39 \\
>39\end{array}$ & $74(490)$ & $141(59.0)$ & $239(100.0)$ & & \\
\hline Total & $172(44.1)$ & $218(55.9)$ & 390 (100.0) & & \\
\hline Gender & & $106(104$ & & & \\
\hline Male & $113(51.6)$ & $106(48.4)$ & $219(100.0)$ & 11.383 & O.001 \\
\hline Female & $59 \quad(34.5)$ & $112(65.5)$ & 171 (100.0) & & \\
\hline Total & $172(44.1)$ & $218(55.9)$ & $390(100.0)$ & & \\
\hline Marital status & & & & & \\
\hline Married & $132(47.1)$ & $148(52.9)$ & $280(100.0)$ & 3.722 & 0.054 \\
\hline Unmarried & $40(36.4)$ & $70 \quad(63.6)$ & $110(100.0)$ & & \\
\hline Total & $172(44.1)$ & $218(55.9)$ & $390(100.0)$ & & \\
\hline Highest education & & & & & \\
\hline None & $25(42.4)$ & $34(57.6)$ & $59(100.0)$ & 0.143 & 0.931 \\
\hline Primary/Secondary & $133(44.6)$ & $165(55.4)$ & $298(100.0)$ & & \\
\hline Tertiary & $14(42.4)$ & $19(57.6)$ & $33 \quad(100.0)$ & & \\
\hline Total & $172(44.1)$ & $218(55.9)$ & $390(100.0)$ & & \\
\hline Occupation & & & & & 0.033 \\
\hline $\begin{array}{l}\text { Skilled workers } \\
\text { Unskilled workers }\end{array}$ & $20(41.7)$ & $28(58.3)$ & $48(100.0)$ & 0.133 & \\
\hline $\begin{array}{l}\text { Unskilled workers } \\
\text { Dependants }\end{array}$ & $127(44.4)$ & $\begin{array}{l}159(55.6) \\
31(55.4)\end{array}$ & $286(100.0)$ & & \\
\hline $\begin{array}{l}\text { Dependants } \\
\text { Total }\end{array}$ & $172(44.1)$ & $218(55.9)$ & $390(100.0)$ & & \\
\hline
\end{tabular}

Problem with tooth/teeth in the past and aware- Factors influencing consultation of traditional ness of traditional healers for dental problems

\section{healers for dental problem}

Eighty one out of the 155 participants with a previous There was no association between sociodemographic history of dental problem were aware that traditional characteristics and previous visitation to a traditiona healers gave dental treatment whereas 91 of the 235 healer (Table 3). Similarly, no significant relationship who claimed not to have had issues with their teeth was found between previous tooth problems and conknew that traditional healers provided dental treatment sulting with a traditional healer for dental problem (Ta$(\mathrm{p}=0.008)$. ble 3).

\begin{tabular}{|c|c|c|c|c|c|}
\hline \multirow[b]{2}{*}{ Variable } & \multicolumn{3}{|c|}{ Had visited traditional dental healers in the past } & \multirow[b]{2}{*}{$x^{2}$} & \multirow[b]{2}{*}{ p value } \\
\hline & $\begin{array}{l}\text { Yes } \\
\text { No (\%) }\end{array}$ & $\begin{array}{l}\text { No } \\
\text { No (\%) }\end{array}$ & $\begin{array}{l}\text { Total } \\
\text { No (\%) }\end{array}$ & & \\
\hline Age group (years) & & & & & \\
\hline$\leq 39$ & $17(17.3)$ & $81(82.7)$ & 98 (100.0) & 0.841 & 0.359 \\
\hline$>39$ & $17(23.0)$ & 57 (77.0) & 74 (100.0) & & \\
\hline Total & $34(19.8)$ & $138(80.2)$ & $172(100.0)$ & & \\
\hline \multicolumn{6}{|l|}{ Gender } \\
\hline Male & $23(20.5)$ & $89(79.5)$ & $112(100.0)$ & 0.119 & 0.730 \\
\hline Female & $11(18.3)$ & $49(81.7)$ & $60(100.0)$ & & \\
\hline Total & $34(19.8)$ & $138(80.2)$ & $172(100.0)$ & & \\
\hline \multicolumn{6}{|l|}{ Marital status } \\
\hline Married & $28(21.4)$ & $103(78.6)$ & $131(100.0)$ & 0.894 & 0.344 \\
\hline Unmarried & $6(14.6)$ & $35 \quad(85.4)$ & $41(100.0)$ & & \\
\hline Total & $34(19.8)$ & $138(80.2)$ & $172(100.0)$ & & \\
\hline \multicolumn{6}{|l|}{ Highest education } \\
\hline None & $7(28.0)$ & $18 \quad(72.0)$ & $25(100.0)$ & 1.341 & 0.511 \\
\hline Primary/Secondary & $24(18.0)$ & $109(82.0)$ & $133(100.0)$ & & \\
\hline Tertiary & $3(21.4)$ & $\begin{array}{lll}11 & (78.6)\end{array}$ & $14(100.0)$ & & \\
\hline Total & $34(19.8)$ & $138(80.2)$ & $172(100.0)$ & & \\
\hline \multicolumn{6}{|l|}{ Occupation } \\
\hline Skilled workers & $6(30.0)$ & 14 (70.0) & $20(100.0)$ & 2.272 & 0.321 \\
\hline Unskilled workers & $25(19.7)$ & $102(80.3)$ & $127(100.0)$ & & \\
\hline Dependants & $3(12.0)$ & $22(88.0)$ & $25(100.0)$ & & \\
\hline Total & $34(19.8)$ & $138(80.2)$ & $172(100.0)$ & & \\
\hline \multicolumn{6}{|c|}{ Previous dental problem } \\
\hline Yes & $13(15.9)$ & $69(84.1)$ & $82(100.0)$ & 1.514 & 0.219 \\
\hline No & $21(23.3)$ & 69 (76.7) & $90(100.0)$ & & \\
\hline Total & $34(19.8)$ & $138(80.2)$ & $172(100.0)$ & & \\
\hline
\end{tabular}

Traditional medical practices have been with indigenous African communities for centuries ${ }^{12}$. Many of these practices have, however been dropped because of improved awareness and access to modern methods of health care or modified as a result of better integration of traditional health practitioners into modern health care ${ }^{4,5,13}$. In this study, $44.1 \%$ of the respondents were aware of the existence and functions of traditioner than what was reported by Bamidele et al. ${ }^{10}$ where $90.4 \%$ of urban residents of south- west Nigeria were aware of the existence of traditional medical care. The major methods of care mentioned by the respondents in that study included traditional bone setting and use of herbs.

These methods have been shown to be associated wit negative health outcomes in the African society ${ }^{13}$. Consequently, the greater awareness of medical rather than dental practitioners of traditional health care may be because there are more negative reports associated with visiting such traditional medical practitioners. Another explanation may be the fact that some of the causes of dental pain may be self-limiting or relieved by other means such as self-medication ${ }^{14}$

Only 9\% of the residents of the peri-urban community surveyed in this study had ever visited a traditional healer for dental problems. This low rate of utilisation of traditional methods for dental care is similar to that rural communities in that country utilised traditional methods for general medical care, very few patronised traditional practitioners for dental care because they perceived that dental care was best in hospital settings, in spite of the distance to those facilities ${ }^{11}$. In addition, the present study showed that there is a significant association between having repeated history of dental problems and being aware of the operations of the traditional oral health care providers. Those who had experienced toothaches in the past were more likely to know that these practitioners offered such services. An explanation for this is that pain is an important factor making people seek any dental treatment option available.

This was further explained by the problem driven approach to conventional oral health care that has been documented as the typical pattern of oral health care al healers on matters of dental problems. This is lowreported from Tanzani ${ }^{11}$. Although residents of two

utilization in Africans ${ }^{15}$. Therefore, there is a close reemblance between the oral health behaviour of Africans, either with conventional or traditional health care ettings.

The major sources of awareness of traditional healers for dental problems in this study were through friends and mass or electronic media. Friends, noted in this study, as the most important source of awareness about traditional practitioners of oral health care may be because of the traditions that exist in the African setting, where individuals are more likely to interact with each ther, have friends outside the immediate environment and be influenced by peers creating awareness outlets to relieve dental pain. Furthermore, the radio and television have been reported as important sources of information about the existence of traditional practitioners of health ${ }^{10}$

The poor degree of regulation of advertisement by the traditional practitioners in sub-Saharan Africa ha contributed to the heavy use of radio jingles and television clips in promoting their existence, often with unsubstantiated claims of medicines that could cure al ailments. Socioeconomic and cultural factors were the most frequent reasons given by inhabitants for visiting traditional healers for dental care. In a society where

poverty is rampant and health insurance is available only to a handful, cost becomes a major consideration in the choice of medical or dental care. In a study conducted among 1,759 adult Tanzanians on the barriers to use of emergency services for oral health care, lack of money to pay for treatment or transportation to the dental clinic were noted as major deterrents to seeking emergency oral health care ${ }^{14}$.

In that study only a quarter of the respondents who had experienced acute dental pain went to a hospital with the majority of respondents using self-medication. Adegbembo ${ }^{16}$ had similarly shown that social class and economic status were significant predictors of visiting dentist.

Male respondents were more likely to be aware of traditional oral health care practitioners than female ones and visited the practitioners more often. The influence of gender on the awareness may be because the male gender has been considered a risk factor of some oral diseases such as periodontal diseases ${ }^{17}$. Therefore, when acute pain sets in following complications of dental 
caries and other periodontal problems, the male looks for the quickest or easiest ways to ameliorate the pain, hence turning to traditional healers.

by gender and previous dental problems. Relapse and 'non-relief of pain' appeared to be the major outcomes of visiting traditional healers for oral health care.

Although many respondents in this study who had visited a traditional healer for relief of pain perceived immediate relief, relapse occurred in nearly half of them and overall relief from pain was reported by only $41.2 \%$. About $40 \%$ of these respondents claimed they had "tooth worm(s)" extracted by the traditional healers. The extraction of "worms" is often interpreted as sign of treatment of the underlying pathology in some African and Latin American countries ${ }^{18,19}$. The immediate relief perceived may be due to the psychological impact posed by the extraction of the "tooth worms" regarded as the causative agent and or the analgesic properties of the concoction administered.

This will need to be further investigated. Moreover the self-limiting effect of some oral diseases may also account for this, as the type of oral disease or condition affecting the respondents as at that time was not known. The effectiveness of the traditional methods of oral health care employed by the inhabitants of the study location is less than optimal with the result that $58.8 \%$ of those who had patronized them vowed never to return. This was further evidenced by the relapse occurring in nearly half of those who had received such treatment. Further reinforcing this, is the finding from a study in South-west Nigeria where more than half of the participants were aware of the side effects of visiting traditional medical practitioners and as much as $47 \%$ felt that visiting a traditional medical practitioner could be injurious to their health ${ }^{10}$, though our stud did not address the issue of side effects.

One limitation of this study was that of not investigating the actual contents of the concoction administered, some of which have been anecdotally reported to contain mixtures of orthodox medications as these may have contributed to the relief experienced by some of the respondents, in the first place, hence totally nullifying any effectiveness earlier attributed to the traditional remedies.

\section{Conclusion}

The study has shown moderate awareness of traditional health care practices in a typical peri-urban community in Ibadan, Nigeria. Such awareness is influenced

\section{References}

Petersen PE. The World Oral Health Report 2003: continuous improvement of oral health in the 21 st century--the approach of the WHO Global Oral Health Programme. Community Dent Oral Epidemiol. 2003;31 Suppl 1:3-23.

3. Beveridge S. Oral health beliefs, traditions, and practices in the Somali culture. 2006. Retrieved November12, 2012 from: http://ethnomed.org/clinical/ oral-health/som-oral-health

4. Agbor AM, Naidoo S, Mbia AM. The role of traditional healers in tooth extractions in Lekie Division, Cameroon. Journal of Ethnobiology and Ethnomedicine. 2011;7:1-8.

5. Aderinokun GA, Lawoyin JO, Onyeaso CO. Effect of two common Nigerian chewing sticks on gingival health and oral hygiene. Odontostomatol Trop. 1999;22(87):13-18

6. Bukar A, Danfillo IS, Adeleke OA, Ogunbodede EO. Traditional oral health practices among Kanuri women of Borno State, Nigeria. Odontostomatol Trop. 2004:27(107):25-31.

7. Elujoba AA, Odeleye O, Ogunyemi C. Review-Traditional medicine Development for medical and dental primary health care delivery system in Africa. Afr Trad Comp Alt Med. 2005;2(1):31-45.

8. Graham EA, Domoto PK, Lynch H, Egbert MA. Dental injuries due to African traditional therapies for diarrhea. West J Med. 2000;173(2):135-137.

9. Rodd HD, Davidson LE. 'Ilko dacowo:'canine enucleation and dental sequelae in Somali children. International Journal of Paediatric Dentistry. 2000;10(4):290-297.

10. Bamidele JO, Adebimpe WO, Oladele EA. Knowlamongst urban residents of Osun state, southwestern Nigeria. African Journal of Traditional, Complementary, and Alternative Medicines. 2009;6(3):281.

11. Sarita PT, Tuominen R. Use of health care services in two rural communities in Tanzania. Community Dent Oral Epidemiol. 1993;21(3):133-135.

2. Morris AG. Dental mutilation in southern Af-
2. Ogunbodede E. Dental care: the role of traditional healers. World Health Forum. 1991;12(4):443edge, attitude and use of alternative medical therapy rican history and prehistory with special reference to the "Cape Flats Smile". SADJ. 1998;53:179-183.

13. Alonge TO, Dongo AE, Nottidge TE, Omololu AB, Ogunlade SO. Traditional bonesetters in south western Nigeria--friends or foes? West Afr J Med. 2004;23(1):81

14. Kikwilu EN, Masalu JR, Kahabuka FK, Senkoro AR. Prevalence of oral pain and barriers to use of emergency oral care facilities among adult Tanzanians. BMC Oral Health. 2008;8:28

16. Adegbembo AO. Household utilization of dental services in Ibadan, Nigeria. Community Dent Oral Epl. 1994:22(5 Pt 1):338-9.

17. Taiwo JO, Jeboda SO, Motayo TO, Obiechina AE. Periodontal health of the elderly people in South East local government area in Ibadan, Nigeria. Afr J Med Sci. 2004 Dec;33(4):285-291.

18. Nations MK, Nuto Sde A. "Tooth worms", poverty tattoos and dental care conflicts in Northeast Brazil. Soc Sci Med. 2002;54(2):229-44

15. Okunseri C, Chattopadhyay A, Lugo RI, McGrath 19. Oke GA, Bankole OO, Denloye OO, Danfillo IS, C. Pilot survey of oral health-related quality of life: a Enwonwu CO. Traditional and emerging oral health cross-sectional study of adults in Benin City, Edo State, practices in parts of Nigeria. Odontostomatol Trop. Nigeria. BMC Oral Health. 2005;5:7. 